\title{
The influence of the solar radiation heat input into the room on the level of energy-efficient thermal protection of the building
}

\author{
Elena Malyavina* and Anastasya Frolova \\ Moscow State University of Civil Engineering, Jaroslavskoe Shosse, 26, Moscow, 129337, Russia
}

\begin{abstract}
The task of increasing the energy efficiency of external enclosing structures is often considered as the need to increase their heat transfer resistance. At the same time, the main indicator of this efficiency is the heat consumption reduction for heating of the buildings having high thermal protection. Despite the fact that Russia is a rather cold country with a long heating period in most of its territory, the lack of accounting the cold consumption in warm period of the year leads to wrong understanding by the specialists of the energy expediency of the building thermal protection level. In today's world, more and more buildings, which have been built, house the civil technologies with high heat emissions, i.e. administrative and office, entertainment, training, shopping and other buildings. These buildings require high energy consumption for cooling, which is often necessary even during the heating period. Taking into account the heat input from the solar radiation with variable intensity throughout the year, the thermal protection level is subject to significant corrections. This is due to the fact that often the cooling of the room is required during the periods when the outdoor temperature is below the maximum allowable room temperature. During these periods, the enhanced thermal protection is an obstacle to the natural heat outflow from the premises. The calculations showed that the higher is the solar radiation heat input, the smaller is the part of energetically feasible buildings according to the basic norms prescribed by the SP 50.13330.2012. And although the sanitary and hygienic requirements show no reasons of the building heat insulation from the energy point of view, the conclusions about the profitability of the building insulation with a reduced basic resistance to heat transfer of walls and coatings of the building are economically significant.
\end{abstract}

\section{Introduction}

The energy saving is a priority in construction. The choice of the appropriate thermal protection of buildings for energy reasons should be considered as the most important task herein [1-12]. This means that the thermal protection of a building should lead to minimal energy consumption by the systems which provide the room thermal microclimate. The

\footnotetext{
Corresponding author: emal@list.ru
} 
Russian normative documents [13] until now, when comparing the thermal protection options, take into consideration only the heating thermal energy consumption from the total energy consumption going to the maintenance of the room thermal conditions. However, it has been repeatedly shown that for buildings in which the required microclimatic conditions are maintained all the year round, the energy consumption shall be taken into account both for heating and cooling of the premises [14-16]. When choosing the appropriate thermal protection, it should be taken into account both the climatic conditions in which the building is located, and its configuration and number of storeys. An important circumstance in this case is the heat supply to the premises of the building. In the works [14-16] we considered administrative and office buildings, which have traditionally shaded windows from the sun in order to avoid glare and additional heat inputs in supplement to the technological ones.

At the same time, there are plenty of other buildings having a working day at the same time from 9 a.m. to 18 p.m, where the solar energy is either not fully shaded or not shaded at all.

The purpose of this article is to determine combinations of the building parameters, the heat input levels therein, as well as the window sun protection levels, which require certain reasonable levels of the thermal protection.

\section{Objects of study}

The study was performed by calculation means. The calculation was made for rectangular buildings with the same width equal to $20.2 \mathrm{~m}$ in external measurement. The length of the buildings varied from $13.6 \mathrm{~m}$ to $115.6 \mathrm{~m}$. All the end walls of the buildings have been solid (without windows). The number of storeys varied from 1 to 40 floors. The glazing of longitudinal walls is presented in two versions: 0.25 ; 0.55 . The windows are thick enough not to take into account the infiltration. Individual characteristics of some buildings are given in the Table 1.

Table 1. Main geometrical characteristics of the buildings.

\begin{tabular}{ccccccr}
\hline \multirow{2}{*}{ Denomination of the value } & \multicolumn{5}{c}{ The building option } \\
\cline { 2 - 7 } & 1 & 2 & 3 & 4 & 5 & 6 \\
\hline Building length, $m$ & 13.6 & 20.4 & 61.2 & 88.4 & 115.6 & 115.6 \\
\hline Number of storeys & 2 & 1 & 15 & 24 & 22 & 40 \\
\hline Building total area, $\mathrm{m}^{2}$ & 549 & 412 & 18544 & 42856 & 51373 & 93405 \\
\hline Area of exterior enclosing structures, $\mathrm{m}^{2}$ & 802 & 729 & 10760 & 22116 & 25638 & 44705 \\
\hline Building volume, $\mathrm{m}^{3}$ & 2143 & 1607 & 72320 & 167140 & 200353 & 364279 \\
\hline Building compactness coefficient & 0.567 & 0.710 & 0.166 & 0.143 & 0.140 & 0.129 \\
\hline
\end{tabular}

The buildings consist of the rooms of the same size of $6.8 \times 10.1 \times 3.9$ (h) $\mathrm{m}$ of four types: ordinary of intermediate floors, ordinary of the top floor, corner on the intermediate floors, corner on the top floor. The rooms have a large depth $(10.1 \mathrm{~m})$, which leads to a significant spread of heat emissions per the area unit of the external enclosing structures. For example, in the middle floor ordinary rooms, the enclosing structures have a total area of $26.5 \mathrm{~m}^{2}$, and in the upper corner ones $-134.6 \mathrm{~m}^{2}$.

Three options of the building thermal protection have been considered. They differ from each other by the heat transfer resistance of the external wall and the coating. For the option 1 , the heat transfer resistance of the outer wall and the coating are close to the prescribed formula (5.4) of SP 50.13330.2012 "Thermal protection of buildings" for sanitary conditions. The option 3 of the thermal protection corresponds to the basic standards, based on the energy saving according to the Table. 3 of the above mentioned SP. For the option 2, 
the heat transfer resistances of the outer walls and coatings have been calculated by the formula (5.1) of the same SP using 0.63 reduction factor for the walls and 0.8 for the coating with respect to the option 3 .

The values of heat transfer resistances, $\mathrm{m}^{2.0} \mathrm{C} / \mathrm{W}$, for external enclosing structures, corresponding to variants 1,2 and 3 as follows: for walls: 1.347 ; 1.704; 2.629; for coating: $1.490 ; 2.871 ; 3.621$. The window heat transfer resistance in all variants is assumed to be $0.54 \mathrm{~m}^{2.0} \mathrm{C} / \mathrm{W}$.

Specific heat input to the premises has been taken into account from 9 a.m. to 18 p.m. and selected at 6 levels: $0 \mathrm{~W} / \mathrm{m}^{2}, 15 \mathrm{~W} / \mathrm{m}^{2}, 30 \mathrm{~W} / \mathrm{m}^{2}, 50 \mathrm{~W} / \mathrm{m}^{2}, 70 \mathrm{~W} / \mathrm{m}^{2}$ and $80 \mathrm{~W} / \mathrm{m}^{2}$. This value does not include solar radiation which penetrates through the windows.

Attention is drawn to the fact that the annual energy consumption considered only the need for buildings in heat and cold to maintain a given thermal microclimate of the premises. No losses due to inefficient operation and additional energy costs for the preparation of the required heating and cooling systems were considered. In the calculations it was assumed that the natural cooling is used at an outdoor temperature not higher than +5 ${ }^{\circ} \mathrm{C}$.

To determine the energy consumption for maintaining a given microclimate of premises with different heat transfer resistances of external enclosing structures, a direct calculation of the unsteady thermal regime of the office premises at different outdoor temperature values has been performed. Non round-the-clock work in the office rooms and, hence, non round-the-clock heat emissions explain the non-stationarity of the thermal process. As a research tool, provision has been made of a calculation program of the room non-stationary thermal regime, which is based on the calculation of finite differences with creation of an implicit difference scheme by the method of thermal balance. The method enables solution of the problem in the most complete formulation, when changing the coefficients of radiant and convective heat emissions on the enclosing structure surfaces without binding the magnitude of the steps in time to the coordinate steps with sufficient accuracy of the obtained result [17].

The calculations were performed at 7 different values of the outdoor air temperature during the year: from the design for heating to calculated for air conditioning in the warm period of the year. The whole year was divided into 7 intervals, where the selected temperature values were their middle points. The duration of the temperature observation was determined by [19] and is given in Table 2.

Table 2. Number of observation days of the outdoor air temperature during the year.

\begin{tabular}{ccc}
\hline $\begin{array}{c}\text { Outdoor air temperature } \\
\text { interval, }{ }^{\circ} \mathrm{C}\end{array}$ & Average interval temperature, ${ }^{\circ} \mathrm{C}$ & Duration, days \\
\hline$+21.75 \leq t$ & +28.5 & 18 \\
\hline$+10 \leq t<+21.75$ & +15 & 114 \\
\hline$+2.5 \leq t<+10$ & +5 & 74 \\
\hline$-1.55 \leq t<+2.5$ & 0 & 8 \\
\hline$-6.25 \leq t<-1.55$ & $-3,1$ & 87 \\
\hline$-19.2 \leq t<-6.25$ & -10.4 & 54 \\
\hline$t \leq-19.2$ & -28 & 9 \\
\hline
\end{tabular}

It was assumed that the object is heated by a Central water heating system in the cold season with local heating devices being equipped by thermostatic valves adjusted to the maintenance of the maximum allowable temperature in the premises. To reduce the room 
temperature to the minimum level to the beginning of the working day, the reduced temperature of the coolant shall be maintained at the heat input into the building during non-working hours. At any outdoor air temperature two restrictions are imposed on the heating power. First, the heating power should not be greater than the power supporting around the clock $20{ }^{\circ} \mathrm{C}$ in the room. Secondly, the limit on the temperature in the room in the heating period should not be below $18^{\circ} \mathrm{C}$ by the beginning of the working day and $24^{\circ}$ $\mathrm{C}$ by the end of the working hours.

\section{Methods of computation of the solar radiation heat energy}

It is known that the intensity of direct and scattered radiation varies from month to month. In addition, the weather conditions change daily. However, the average monthly sums of the intensity of direct and scattered solar radiation in the long-term period of time are given by climatologists in reference books [19].

The input of total solar radiation in each month of the year on a horizontal surface is the starting material for the calculation of the heat input into the rooms through translucent structures [1].

In the reference books [19] the actinometric measurers fixe separately the monthly totals of solar radiation with cloud (the actual conditions of cloudiness) and clear (cloudless) sky. Monthly amounts of solar radiation under the actual cloud conditions are determined by averaging the measurement data under the actual cloudiness with any shape and any number of clouds. At the same time, measurements in a clear sky are not taken into account. Therefore, for each month provision shall be made of summarizing the amount of solar radiation in the two states of the sky [20]. In this case, the monthly sum of the total solar radiation coming to the vertical surface takes into account the direct, scattered and reflected solar radiation by the formula:

$$
\begin{gathered}
I_{\text {vert }, m}=\left(S_{\text {clear,hor }, m}+S_{\text {cloud,hor }, m}\right) \cdot K_{\text {h.vert }, m}+\left(D_{\text {clear,hor }, m}+D_{\text {cloud,hor }, m}\right) / 2+\left(I_{\text {clear,hor }, m}+I_{\text {cloud,hor }, m}\right)^{\mathrm{x}} \\
{ }^{\mathrm{x}} A_{\mathrm{m}} / 200
\end{gathered}
$$

where: $S_{\text {clear,hor, } m}, S_{\text {cloud,hor }, m}$ - monthly sums of direct solar radiation in clear days and under actual cloud conditions on horizontal surface in a month $\mathrm{m}, \mathrm{MJ} / \mathrm{m}^{2}$,

$D_{\text {clear,hor, } m}, D_{\text {cloud,hor, } m}$ - monthly totals of diffuse solar radiation on clear days and when the actual cloud cover on the horizontal surface in the month $\mathrm{m}, \mathrm{MJ} / \mathrm{m}^{2}$,

$I_{\text {clear,hor }, m}, I_{\text {cloud,hor, } m}$ - monthly sums of total solar radiation on clear days and under actual cloud conditions on a horizontal surface in a month $\mathrm{m}, \mathrm{MJ} / \mathrm{m}^{2}$,

$K_{\mathrm{h} . v e r t, m}-$ coefficient of conversion of direct solar radiation from a horizontal surface to a vertical, oriented to the South side, in the month $\mathrm{m}$,

Am - albedo of the underlying surface in month $\mathrm{m}$.

The Table 3 presents the monthly amounts of solar radiation on cloudy and cloudless days, which served as the initial information for further calculations, as well as the coefficients of conversion of direct solar radiation from a horizontal surface to a vertical southern orientation, as well as the albedo of the underlying surface in different months of the year.

In order to obtain the sum of the solar radiation inlet on a horizontal surface at a certain temperature range specified in the Table 2, provision has been made of consideration of the months during which this temperature is observed as per [18]. The average total solar radiation coming to the horizontal surface in each of the intervals given in the Table 2 was calculated and multiplied by the number of days in the interval.

When considering heat inlets from the solar radiation, the coefficients of the total solar energy transmission by 0.72 double window glazing unit, 0.8 sashes and the protection 
facilities at two levels: 0.4 and 1 were taken into account. In the latter case, the lack of sun protection is considered.

Table 3. Basic input data for the calculation of heat inlet from solar radiation.

\begin{tabular}{|c|c|c|c|c|c|c|c|c|c|c|c|c|}
\hline \multicolumn{13}{|c|}{ Monthly sums of solar radiation, $\mathrm{MJ} / \mathrm{m}^{2}$} \\
\hline Month of the year & 㥕 & 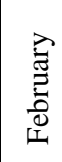 & 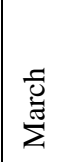 & $\overline{\vec{z}}$ & 胥 & $\stackrel{\Xi}{\Xi}$ & $\stackrel{\lambda}{\Xi}$ & $\begin{array}{l}\overrightarrow{0} \\
\overrightarrow{50} \\
\vec{Z}\end{array}$ & 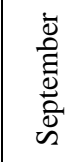 & $\begin{array}{l}\dot{\bar{D}} \\
\stackrel{0}{0} \\
\dot{0}\end{array}$ & $\begin{array}{l}\dot{\bar{D}} \\
\text { है } \\
\text { Dे } \\
\text { z }\end{array}$ & 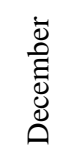 \\
\hline $\begin{array}{l}\text { Direct solar radiation } \\
\text { under real conditions of } \\
\text { cloudiness on a horizontal } \\
\text { surface }\end{array}$ & 12 & 43 & 109 & 176 & 278 & 319 & 286 & 220 & 124 & 44 & 14 & 5 \\
\hline $\begin{array}{l}\text { Scattered solar radiation } \\
\text { at actual cloud conditions } \\
\text { on a horizontal surface }\end{array}$ & 55 & 94 & 173 & 229 & 287 & 305 & 301 & 254 & 172 & 101 & 49 & 35 \\
\hline $\begin{array}{l}\text { Total solar radiation } \\
\text { at the actual cloud cover } \\
\text { on a horizontal surface }\end{array}$ & 67 & 137 & 282 & 405 & 565 & 624 & 587 & 474 & 296 & 145 & 63 & 40 \\
\hline $\begin{array}{l}\text { Direct solar radiation in } \\
\text { clear days on a horizontal } \\
\text { surface }\end{array}$ & 57 & 138 & 303 & 434 & 628 & 707 & 686 & 472 & 333 & 211 & 88 & 38 \\
\hline $\begin{array}{l}\text { Scattered solar radiation } \\
\text { in clear days on a } \\
\text { horizontal surface }\end{array}$ & 47 & 72 & 125 & 170 & 192 & 176 & 159 & 164 & 129 & 90 & 52 & 35 \\
\hline $\begin{array}{l}\text { Total solar radiation in } \\
\text { clear days on a horizontal } \\
\text { surface }\end{array}$ & 104 & 210 & 428 & 604 & 820 & 883 & 845 & 636 & 462 & 301 & 140 & 73 \\
\hline $\begin{array}{l}\text { Total solar radiation on } \\
\text { the vertical surface of the } \\
\text { southern orientation }\end{array}$ & 461 & 706 & 965 & 839 & 883 & 850 & 839 & 837 & 805 & 707 & 519 & 330 \\
\hline $\begin{array}{l}\text { Direct and diffuse solar } \\
\text { radiation to the southern } \\
\text { surface in a cloudless sky } \\
\text { beforel the working hours }\end{array}$ & 4,8 & 25,7 & $\$ 2,2$ & 70,35 & 71,0 & 66,4 & 68,33 & 368,82 & 60,5 & 36,96 & 14,87 & 2,79 \\
\hline \multicolumn{13}{|c|}{ Auxiliary values } \\
\hline $\begin{array}{l}\text { Direct solar radiation } \\
\text { conversion factor from } \\
\text { horizontal surface to the } \\
\text { vertical one }\end{array}$ & 5,1 & 2,8 & 1,6 & 0,9 & 0,55 & 0,44 & 0,48 & 0,74 & 1,26 & 2,2 & 4,2 & 6,1 \\
\hline Albedo, $A, \%$ & 64 & 67 & 50 & 18 & 21 & 21 & 20 & 21 & 21 & 23 & 40 & 58 \\
\hline
\end{tabular}

\section{The main parameters for generalization of the calculation results}

As the main parameter for summarizing the calculation results [14-15] provision has been made of the specific heat inlets into the building rooms per $1 \mathrm{~m}^{2}$ of the floor. As it has been specified above, these heat inputs, do not take into account the heat of solar radiation heat inlets, which enter through the windows.

The second important parameter is $\mathrm{K}_{\mathrm{m}}$ - the total heat transfer coefficient of the building. This coefficient is accepted as a characteristic of the thermal protection properties 
of the building in SP 50. 13330.2012 "Thermal protection of buildings", the updated version of SNiP 23.02.2003. This coefficient includes the size and the heat resistance of all the enclosing structures of the building that make its thermal protection enclosing:

$$
K_{m}=\frac{1}{A_{e}^{\text {sum }}} \sum_{i} \frac{A_{i}}{R_{o . i}^{r}}
$$

where $A_{\mathrm{e}}$ sum - the sum of the areas of all external protections of a heat-shielding cover of the building, $\mathrm{m}^{2}$;

$A_{i^{-}}$area of the i-th fragment of the building heat shield, $\mathrm{m}^{2}$;

$R_{o, i}^{\mathrm{r}}-$ reduced resistance to heat transfer of the i-th fragment of the building heat enclosure, $\left(\mathrm{m}^{2} \cdot{ }^{\circ} \mathrm{C}\right) / \mathrm{W}$.

In addition, it was previously found [16] out, that the building parameter combination zone, which transfers the thermal protection to a single level, is highly influenced by the size of the window. From the thermal engineering point of view a window is a specific enclosing structure: first, it has a certain heat transfer resistance which remains constant in the presented calculations for all options of the building thermal protection and therefore cannot be considered as an ordinary design structure. Secondly, the problem that is under solution in this article, the window is a source of penetration of solar radiation into the room, and the loads depend on the size of the window, both on the room heating systems on their cooling systems.

\section{Calculation results}

The calculation investigated the need for heat and cold to maintain the given thermal mode in the building rooms during the year. Moreover, the need for heating at night and cooling during the day was taken into account in certain days of the cold period of the year. The requirement to take into account the year-round maintenance of the specified temperature conditions in the premises has been confirmed [18] by the fact that the cold is required for a long period of time when the outdoor air temperature is below the maximum permissible room temperature of $24^{\circ} \mathrm{C}$. At this time, the increase in resistance to heat transfer of the walls and the coatings plays a negative role, as it prevents the natural outflow of heat from the room.

In Moscow, the heating period has an average duration of 205 days, that is, most of the year. Even if we do not take into account the economic component of a higher price of cold compared to the thermal energy, the amount of cold for the warm period of the year is a significant amount of the amount of heat for the heating period. It is clear that the more internal heat in the room is, the greater the load on the cooling system is, so more houses shall reasonably have not the most powerful thermal protection. In this regard, the study of the influence of heat input from the solar radiation is a quite timely task.

Figure 1 shows the combinations zones of levels of technological heat inlets and the total heat transfer coefficient of buildings. It is seen, that the higher the level of specific heat and the higher the value of the total heat transfer coefficient are, the more profitable is to provide thermal insulation according to the option 2. This option applies to the buildings with reduced heat transfer resistance of walls and coatings compared to the basic option 3 . It is interesting to note that the insulation of the building for sanitary reasons to insulate energy is not advisable ever. The values of the total heat transfer coefficient increase with the increase in the volume of the building, the proportion of its glazing and a decrease in the level of thermal protection of the building enclosing structures.

The unpainted areas in figure 1 refer to the buildings higher than 40 floors with a plan size of more than $115.6 \times 20.2 \mathrm{~m}$, which were not considered. 


\section{Conclusions}

Solar radiation heat inputs create an additional load on the cooling system of the building in the transitional and warm periods of the year. In the cold period of the year these heat inputs reduce the load on the heating systems. However, with specific technological heat inputs into the room during working hours of $40 \mathrm{~W} / \mathrm{m}^{2}$ and above, there are cases when, even during the heating period, the solar radiation plays a negative role, since its action coincides in time with technological heat inputs.

a)

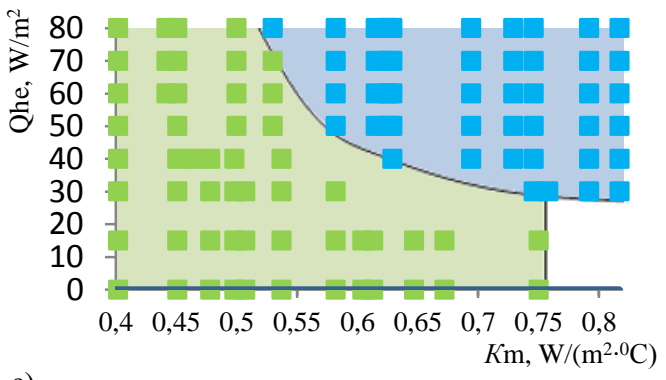

c)

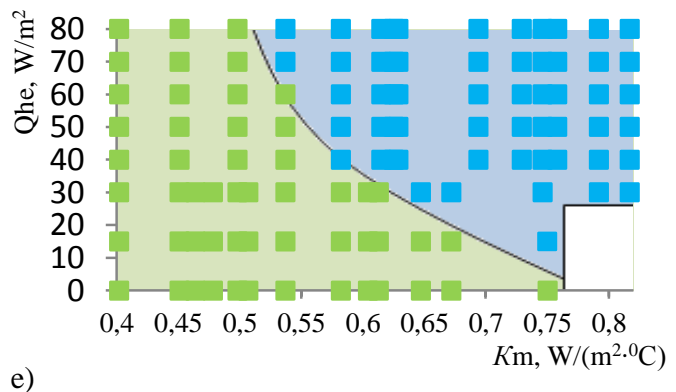

b)

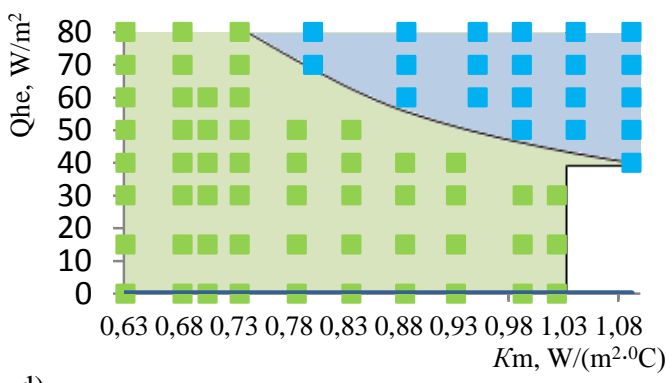

d)
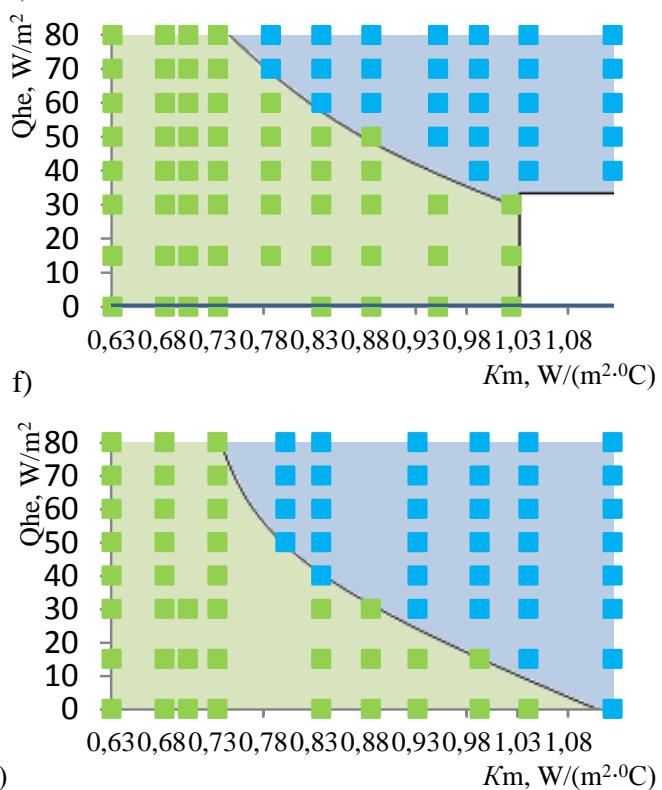

Fig. 1. Energy-efficient options for thermal protection of buildings a), c), e) - with a share of the facade glazing $0.25, b), d), f$ ) - with a share of the facade glazing $0.55 ; a), b$ ) - with full shading; c), d) - with sun protection coefficient 0.4 ; e), f) - in the absence of shading. Symbols: blue area thermal protection with reduced coefficients in relation to the basic thermal protection (option 2); green area - basic thermal protection (option 3).

\section{References}

1. V.I. Bodrov, A.A. Smyko, J. C.O.K. 7, 52 - 55 (2014)

2. V. Veselov, V.D. Kornienko, J. Building materials, equipment, technologies of the XXI century $\mathbf{7}-\mathbf{8}, 210-211(2016)$ 
3. D.V. Berezin, J. Academic Bulletin of the Ural TsNII project RAASN 3, $84-88$ (2016)

4. A.I. Ananyev, J. AVOK 3, 70 - 73 (2018)

5. O.I. Lobov, A.I. Ananyev, A.G. Rymarov, J. Industrial and civil engineering 11, 56 60 (2016)

6. I.L. Shubin, J. AVOK 7, 4 - 10 (2018)

7. W. Tian, S. Yang, J. Zuo, Z.Y. Li, Y.L. Liu, J. Building Simulation 10, 11 - 24 (2017)

8. L. Liu, D. Wu, X. Li, S. Hou, C. Liu, P. Jones, J. Building Simulation 10, 625 - 641 (2017)

9. D. Ndiaye, J. Building Simulation 11, 435 - 438 (2018)

10. Y. Kharbouch, L. Ouhsaine, A. Mimet, M. El Ganaoui, J. Building Simulation 11, $1083-1093$ (2018)

11. E.-H.D. Lamrhari, B. Benhamou, J. Building Simulation 11, 1123 - 1144 (2018)

12. E.C. Lucchino, F. Goia, G. Lobaccaro, G. Chaudhary, J. Building Simulation 12, 3 27 (2019)

13. SP 345.1325800.2017. The buildings are residential and public. Rules of design of thermal protection (Ministry Of Construction, Moscow, 2017)

14. E.G. Malyavina, A.A Frolova, J. Advances in Intelligent Systems and Computing 692, 498 - 511 (2017)

15. E.G. Malyavina, A.A. Frolova, J. High school Bulletin. Construction 4, 78 - 83 (2013)

16. E.G. Malyavina, A.A Frolova, J. AVOK 1, 68 - 73 (2017)

17. B.M. Berkovskiy, E.F. Nogotov Difference methods of research of heat transfer problems (Science and technology, Minsk, 1976)

18. V.K. Savin, Construction climatology: Reference book to SniP 23-01-99* (Sc. And research institute of the construction physics of RAASN, Moscow, 2006)

19. Scientific and applied reference book on the climate of the USSR. Episode 3. Multiyear data. (Hydrometeoizdat, St. Petersburg, 1989 - 1998)

20. E.V. Korkina, E.V. Gorbarenko, V.G. Gagarin, I. Shmarov, J. Housing construction 6, $27-33(2017)$ 